\title{
Numerical Simulation of Empty-Hole Effect during Parallel-Hole Cutting under Different In Situ Stress Conditions
}

\author{
Zhengyu Wu $\left(\mathbb{D},{ }^{1}\right.$ Dayou Luo $\mathbb{D}^{2},{ }^{2}$ Feng Chen, ${ }^{1}$ and Wulin Huang ${ }^{3}$ \\ ${ }^{1}$ School of Engineering, Fujian Jiangxia University, 2 Xiyuangong Road, Fuzhou 350108, China \\ ${ }^{2}$ Engineering, Francis College of Engineering, University of Massachusetts Lowell, Lowell, MA 01854, USA \\ ${ }^{3}$ School of Resource and Safety Engineering, Central South University, 932 South Lushan Road, Changsha 410083, China \\ Correspondence should be addressed to Dayou Luo; dayou_luo@uml.edu
}

Received 25 September 2020; Revised 2 December 2020; Accepted 15 January 2021; Published 8 February 2021

Academic Editor: Xun Xi

Copyright ( $\odot 2021$ Zhengyu Wu et al. This is an open access article distributed under the Creative Commons Attribution License, which permits unrestricted use, distribution, and reproduction in any medium, provided the original work is properly cited.

With the progress of deep mining in mine exploitation, the effect of the in situ stress field plays a more and more significant and crucial role in rock blasting. To uncover the impact of in situ stress field on empty-hole effect during parallel-hole cutting, the distribution and the trend of changes in dynamic stress around empty hole during blasting under different in situ stress conditions are simulated based on the basic model for parallel-hole cutting using 3D finite element analysis software ANSYS/LS-DYNA and implicit-explicit analysis method. Subsequently, the law of variation in the empty-hole effect under different in situ stress conditions is determined, and the effects of horizontal and vertical stress fields are analyzed in detail. The simulation results show that the overall increase in in situ stress can facilitate compressive failure and inhibit tensile failure in the rock mass around an empty hole during blasting. When empty holes are arranged horizontally, the effect of the vertical stress field is consistent with that of the in situ stress field, while the effect of the horizontal stress field is opposite to that of the in situ stress field. With the increased stress, the inhibitive effect of the vertical stress field on tensile stress around an empty hole is remarkably stronger than that of the horizontal stress field. Finally, the numerically simulated results are verified by the theoretical calculation. This study can provide new insight and a simple but accurate numerical simulation method to investigate how the in situ stress field affects the emptyhole effect, especially in deep mining.

\section{Introduction}

With the depletion of mineral resources in the shallow, their exploitation progressively deepens into the Earth (normally up to $1000 \mathrm{~m}$ ) [1,2]. For example, the average depth of metal mines in South Africa has reached $2000 \mathrm{~m}$, the Western Deep Level gold mine has reached $4800 \mathrm{~m}$ [3], and the borehole has reached $6779 \mathrm{~m}$ in the Baltic Shield [4]. In such extreme deep mining, some deemed as negligible problems in shallow depths turn to be very crucial and intractable, i.e., high stress, high temperature, high water pressure, and the disturbance resulted from mining activities, which may lead to sudden and unpredictable destruction of the rock mass [5-8]. Regarding the in situ stress field, existing theoretical and experimental studies show that the interaction between the explosive stress field created by blasting and the in situ stress field will enhance or weaken rock fragmentation effect [9-11]. Due to the complexity of blasting process and the limitations of field test conditions, numerical simulation has gradually become an alternative and desired method to study empty-hole effect apart from theoretical analysis and field test [12-15].

There are several investigations that have been conducted considering the in situ stress field in deep mining both in field testing and numerical simulation [16, 17]. Zhu et al. [18] modeled a FLAC3D model to evaluate the stability of pillars, the long-term stability, and distribution laws of overlying loads. Chen et al. [19] conducted the numerical simulation of double-hole blasting under different in situ stress conditions and found that higher initial in situ stress had a stronger inhibitive effect on the propagation of fractures created by blasting. Zubelewicz 
and Mroz [20] found that the effect of the initial in situ stress field on explosive stress waves was not significant near the explosion cavity and the propagation law of explosive stress waves changed under the action of high in situ stress.

Furthermore, parallel-hole cutting is a simple but efficient method for rock blasting. In the process of rock fragmentation by parallel-hole cutting, existing empty holes provide new free faces, and the stress distribution around empty holes changes, leading to a stress concentration around empty holes that results in increased rock-breaking efficiency [21], which is known as an empty-hole effect during parallel-hole cutting [22]. Extensive research efforts have been performed in the empty-hole effect [23-25]. Li et al. [26] identified the law of stress distribution during parallel-hole cutting using a numerical simulation method. Wang et al. [27] and Zheng et al. [28] analyzed the stress field around large-diameter empty holes in the vertical shaft and calculated relevant parameters using a numerical simulation method. However, the impact of in situ stress field on emptyhole effect was not considered in the studies as mentioned above. Moreover, the empty-hole effect in deep mining is still poorly understood, which calls for more relevant research efforts.

In the current paper, to analyze the effect of in situ stress field on parallel-hole cutting and improve rock fragmentation efficiency during blasting, the distribution and trend of changes in dynamic stress around empty holes under different in situ stress conditions are numerically simulated using 3D finite element analysis software ANSYS/LS-DYNA and implicit-explicit analysis method. The impact of different in situ stress conditions and the magnitude of in situ stress on the empty-hole effect is analyzed, and the rationality of numerical simulation is verified through a theoretical calculation using the Schwarz alternating iteration method based on elastic mechanics.

\section{Methodology}

In the real blasting process, the rock mass near an empty hole may be displaced or crushed under the action of explosive stress, which makes it very difficult to analyze the empty-hole effect under in situ stress conditions using field test. To address this challenge, the distribution of and the changes in stress around empty holes under different in situ stress conditions during parallel-hole cutting are identified through numerical simulation based on literature [15]. The numerical simulation is carried out using ANSYS/LS-D YNA and implicit-explicit analysis method. The implicitexplicit analysis is a special computational analysis method embedded in ANSYS/LS-DYNA, which can simulate and reproduce linear static and nonlinear dynamic combined stress loading patterns. Specifically, this method can simulate the in situ stress field and the explosive stress field by applying linear static constraint and nonlinear dynamic constraint in implicit analysis, respectively. Furthermore, the empty-hole effect can be reproduced, which is generated by blasting under in situ stress conditions objectively and reasonably.
In the process of performing the implicit-explicit analysis, only the objects involved in the implicit analysis are modeled during the implicit analysis, without considering the corresponding "parts" required by the explicit analysis. After the implicit analysis is completed, the corresponding unit type conversion is required. Then, by defining new element types and materials, models required for explicit analysis are created and a new "part" list is generated. Finally, all nodes are selected, the implicit solution result file is read into the dynamic relaxation solution, the stress is initialized to the corresponding part, the necessary constraints and load conditions are applied, and the explicit solution is completed. In the above process, the dynamic relaxation process is to perform a steady-state or quasistatic analysis. Thus, the displacement and blasting thermal effects which resulted from the implicit analysis could be applied as body loads to the corresponding nodes, which in turn realize the stress of the corresponding components' initialization. The initial condition can be used for further analysis

2.1. Geometry and Constraint Conditions. John [29] indicated that the basic model for parallel-hole cutting can be simplified into a model in which a single blast hole and a single empty hole are arranged parallel to each other and the cylindrical explosion cavity extends infinitely in the axial direction. Therefore, this problem may be deemed as a planar axisymmetric problem. To study the distribution of dynamic stress between the blast and empty holes under different in situ stress conditions, the basic horizontal plane is taken as the object of study, and relevant parameters and in situ stress loading method are determined according to the rock cutting parameters and basic cutting mode adopted at a mine [30], as shown in Figure 1.

Note that coupled explosive loading method is adopted in the current study; the blast hole and the empty hole are both $80 \mathrm{~mm}$ in diameter; moreover, the spacing between the blast and empty holes is $200 \mathrm{~mm}$. Considering the size effect of the modelling, the horizontal and vertical edge lengths of rock mass in the model are designed to be $1000 \mathrm{~mm}$ and $400 \mathrm{~mm}$, respectively. As the current simulation can be assigned to a plane strain problem, it can be solved by using a single-layer grid structure, and constraints are applied in the direction of model thickness. Moreover, since the computational model is symmetrical, displacement constraints are applied to the model's left and lower boundaries, vertical in situ stress $p$ is applied to the upper boundary, and horizontal in situ stress $q$ is applied to the right boundary for implicit computation and analysis. The same constraints as those for implicit analysis are applied regarding the explicit computation and analysis, reflecting conditions are applied to the wall of the empty hole, and nonreflecting conditions are applied to all boundaries of the rock mass model.

2.2. Material Properties. For implicit analysis, the rock mass is a granular material. The compressive yield strength of such material is much higher than its tensile yield strength, and the grains in it will swell when it is sheared. The Drucker-Prager yield criterion is used, and quartz is selected as the 


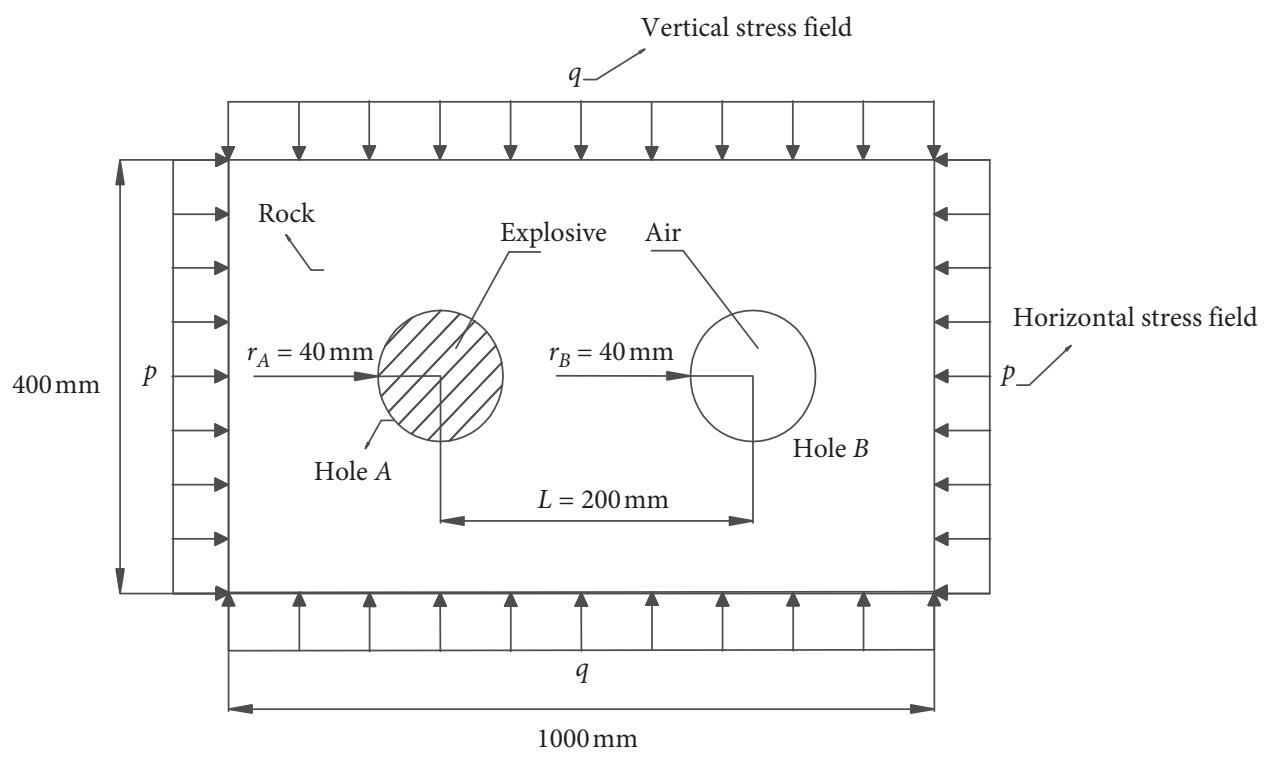

FIgURE 1: Schematic of the numerical simulation model.

rock mass, which is adapted from [1]. The physical and mechanical parameters of quartz rock are listed in Table 1.

For implicit-explicit analysis, the geometric model only involves two materials, namely, rock and explosive. Rock parameters are the same as those listed in Table 1 and No. 2 rock blasting emulsion explosive is used. As verified in the previous publication [31-33], the material model * MAT_HIG H_EXPLOSIVE_BURN embedded in LS-DYNA can be used, and the JWL equation of state is selected and used to describe the state of stress variation under dynamic and static combined loads. The detailed parameters are listed in Table 2. As the rock mass near the blasting area will be a failure during the explosion, it is reasonable to select the plastic kinematic model $*$ MAT_PLASTIC_KINE_MATIC as the rock mass computational model [29].

2.3. In Situ Stress Loading Schemes. As there are references, it is believed that the direction of the in situ stress has different effects on the dynamic stress around the hole during blasting. Therefore, in order to study the distribution process and change trend of the specific dynamic stress, the following assumptions are made during the numerical simulation: (1) the in situ stress is a binary plane and (2) the in situ stress is only divided into horizontal ground stress and vertical ground stress. Finally, three different schemes were designed to study the influence of different in situ stress characteristics on the empty-hole effect including (1) the impact of the overall change of the in situ stress on the empty-hole effect, (2) the influence of the vertical stress field change on the empty-hole effect, and (3) the influence of horizontal stress field changes on the empty-hole effect.

The specific scheme and parameter setting values are shown in Table 3. In the table, $\lambda=q / p$ is the lateral pressure coefficient, which is used to distinguish the change of the stress field.

\section{Numerical Simulation Results and Analysis}

In the current study, both implicit and implicit-explicit analyses are conducted, and the cloud charts of dynamic stress concentration around the hole under No. 2 condition $(p=q=2 \mathrm{MPa})$ in Scheme I before and after blasting are given. Figure 2 shows stress concentration around the hole under the action of the in situ stress field for implicit analysis, and Figure 3 shows dynamic stress concentration around the empty hole under the action of the in situ stress field for implicit-explicit analysis.

In Figure 2, it can be observed that under the action of the in situ stress field, stress is concentrated around the hole, and in particular, a shape similar to a water droplet appears on the side of the hole facing the blast hole. This indicates that the exiting empty hole in the model guides stresses to distribute along the line between the centers of the blast and empty holes, which is possibly contributed to the effect of the in situ stress field; stress concentration around a single hole will further lead to new stress concentrations around surrounding holes; therefore, stress will be concentrated on the side of one hole facing the other hole when two holes exist. Wang [35] and Zhai et al. [36] found a similar phenomenon with model experiments in the laboratory, which confirmed the accuracy of this numerical simulation result.

In Figure 3, it can be observed that before blasting takes place $(t=0 \mu \mathrm{s})$, the stress around the hole has already increased, indicating that the result of implicit analysis has already been applied as a "preload" in the model when the implicit-explicit analysis is commenced. After blasting takes place, the stress around the empty hole is affected by the reflection of explosive stress at the boundary of the empty hole, and when $t=270 \mu$ s, remarkable tensile stress occurs on the side facing the blast hole, which is in high agreement with the field testing results described by Langefors and Kihlström [37]. 
TABLE 1: Quartz rock mechanical parameters [26].

\begin{tabular}{|c|c|c|c|c|c|}
\hline Poisson's ratio & Density & Elastic modulus (GPa) & Compressive strength (MPa) & Tensile strength (MPa) & Longitudinal wave velocity \\
\hline 0.21 & $\begin{array}{c}2790 \mathrm{~kg} / \\
\mathrm{m}^{3}\end{array}$ & 23.03 & 17.40 & 3.06 & $5000 \mathrm{~m} / \mathrm{s}$ \\
\hline
\end{tabular}

TABLE 2: Parameters of the explosive and its equation of state.

\begin{tabular}{lcccccc}
\hline Density $\left(\mathrm{g} / \mathrm{cm}^{3}\right)$ & Detonation velocity $(\mathrm{m} / \mathrm{s})$ & $A(\mathrm{GPa})$ & $B(\mathrm{GPa})$ & $R_{1}$ & $R_{2}$ & $\omega$ \\
\hline 1.3 & 3300 & 215.2 & 0.179 & 4.3 & 0.9 & 0.15 \\
\hline
\end{tabular}

Note: $A, B, R_{1}, R_{2}$, and $\omega$ are parameters related to the JWL equation of state [34].

TABLE 3: Comparison of different schemes and parameter setting.

\begin{tabular}{|c|c|c|c|c|c|}
\hline Scheme & No. & $q(\mathrm{MPa})$ & $p(\mathrm{MPa})$ & $\lambda$ & Purpose \\
\hline \multirow{4}{*}{ I } & 1 & 0 & 0 & 1 & \multirow{4}{*}{ The impact of overall changes in the in situ stress field } \\
\hline & 2 & 2 & 2 & 1 & \\
\hline & 3 & 5 & 5 & 1 & \\
\hline & 4 & 10 & 10 & 10 & \\
\hline \multirow{4}{*}{ II } & 1 & 2 & 0 & $+\infty$ & \multirow{4}{*}{ The impact of changes in the vertical stress field } \\
\hline & 2 & 2 & 2 & 1 & \\
\hline & 3 & 2 & 5 & 0.4 & \\
\hline & 4 & 2 & 10 & 0.2 & \\
\hline \multirow{4}{*}{ III } & 1 & 0 & 2 & 0 & \multirow{4}{*}{ The impact of changes in the horizontal stress field } \\
\hline & 2 & 2 & 2 & 1 & \\
\hline & 3 & 5 & 2 & 2.5 & \\
\hline & 4 & 10 & 2 & 5 & \\
\hline
\end{tabular}

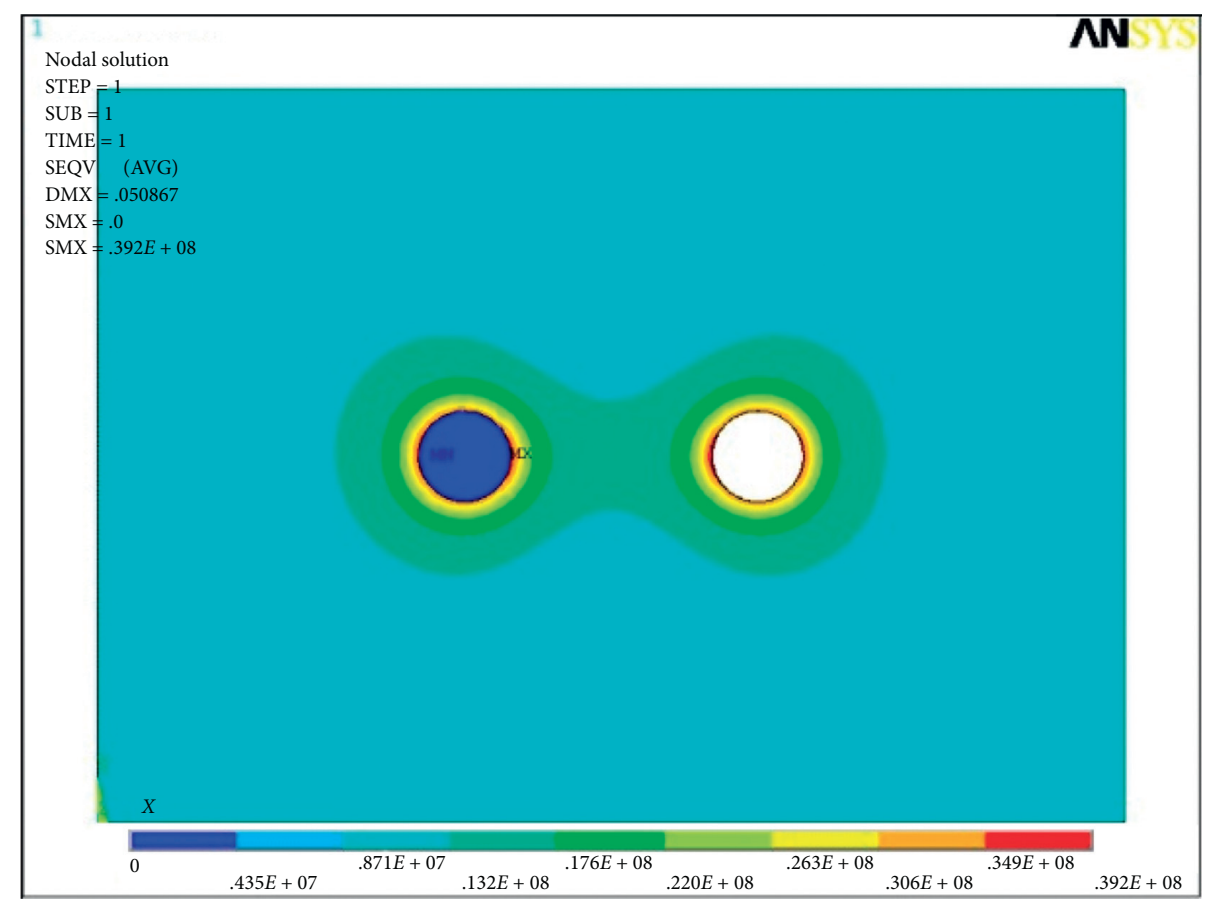

FIGURE 2: Cloud chart of stress distribution around the empty hole in the in situ stress field. 


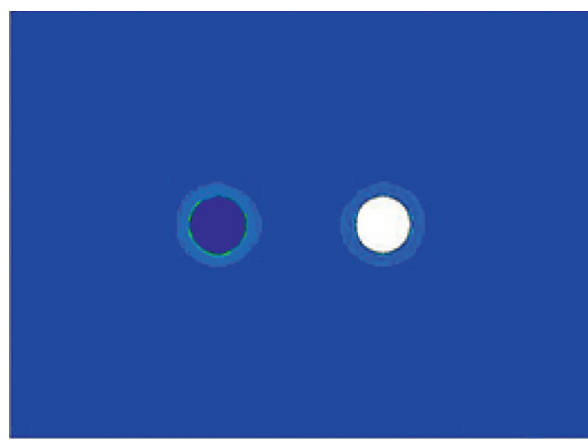

(a)



(c)



(b)

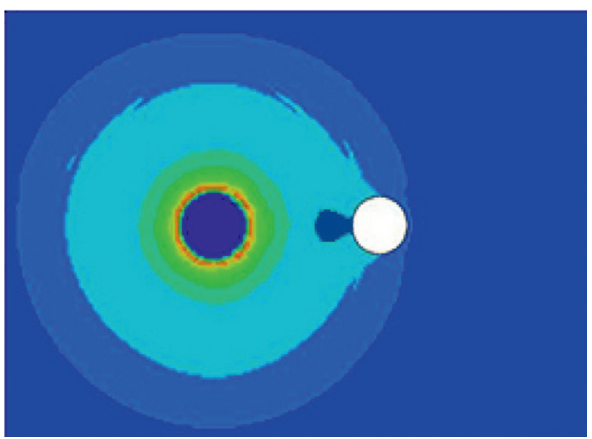

(d)

Figure 3: Cloud chart of dynamic stress distribution for implicit-explicit solution. (a) $t=0 \mu \mathrm{s}$, (b) $t=90 \mu \mathrm{s}$, (c) $t=180 \mu \mathrm{s}$, and (d) $t=270 \mu \mathrm{s}$.

Figure 4(a) shows the impact of overall changes in the in situ stress field on dynamic stress distribution around the empty hole during blasting when $t=270 \mu$ s (when the tension zone has the largest area) for Scheme I. Because the changes in tension zone displayed in the cloud chart are not clear enough, "the horizontal range of tension zone around the empty hole $(D) /$ the diameter of the empty hole $\left(r_{B}\right)$ " is used to measure the impact of changes in in situ stress on the tension zone. The trend of changes in the tension zone is shown in Figure 4(b). Additionally, as the cloud chart of dynamic stress distribution cannot accurately show the changes in stress around the empty hole, 2081 points on the edge of the empty hole facing the blast hole are selected for analysis. The curves reflecting changes in stress are shown in Figure 5.

From Figure 4, it can be found that as in situ stress increases (from $0 \mathrm{MPa}$ to $10 \mathrm{MPa}$ ) and when lateral pressure coefficient $\lambda$ remains unchanged, the compression zone near the empty hole increases while the tension zone near the empty hole decreases $\left(D / r_{B}\right.$ decreases from 0.62 to 0.34 ). From Figure 5, it can be known that before explosive stress is transmitted to the selected points, these points are subject to stable compressive stress under the action of the in situ stress field, and such compressive stress increases (from $0 \mathrm{MPa}$ to $18.57 \mathrm{MPa}$ ) with the increase in in situ stress. When explosive stress is transmitted to the selected points $(t=230 \mu \mathrm{s})$, as in situ stress increases, the combined compressive stress on these points increases from 17.43 $\mathrm{MPa}$ to $36.72 \mathrm{MPa}$ while the combined tensile stress decreases from $45.55 \mathrm{MPa}$ to
16.44 $\mathrm{MPa}$. This trend of changes indicates that the overall increase in in situ stress can inhibit the tensile failure of rock mass near the empty hole during blasting and facilitate the compressive failure of the same rock mass.

Figure 6(a) shows the impact of changes in the vertical stress field on dynamic stress distribution around the empty hole during blasting when $t=270 \mu \mathrm{s}$. Figure 6(b) shows a curve reflecting the changes in the tension zone with the changes in the vertical stress field. Figure 7 shows the curves reflecting the changes in stress at 2081 points under the action of the combined stress field for Scheme II.

From Figure 6, it should be noted that as vertical stress increases (from $0 \mathrm{MPa}$ to $10 \mathrm{MPa}$ ) and as lateral pressure coefficient $\lambda$ decreases, the tension zone near the empty hole decreases $\left(D / r_{B}\right.$ decreases from 0.64 to 0.41$)$. Figure 7 shows that when explosive stress is transmitted to the calculated points, the initial maximum combined compressive stress around the empty hole increases (from $18.23 \mathrm{MPa}$ to $38.56 \mathrm{MPa}$ ) while the combined tensile stress decreases (from $48.45 \mathrm{MPa}$ to $15.56 \mathrm{MPa}$ ). These phenomena indicate that when empty holes are arranged horizontally, the changes in vertical stress field have the same impact on the empty-hole effect as the overall changes in the in situ stress field, and the increase in vertical stress can inhibit the tensile failure of rock mass near the empty hole during blasting and facilitate the compressive failure of the same rock mass.

Figure 8(a) shows the impact of changes in the horizontal stress field on dynamic stress distribution around the empty hole during blasting when $t=270 \mu \mathrm{s}$. Figure 8(b) shows a curve reflecting the changes in the tension zone 

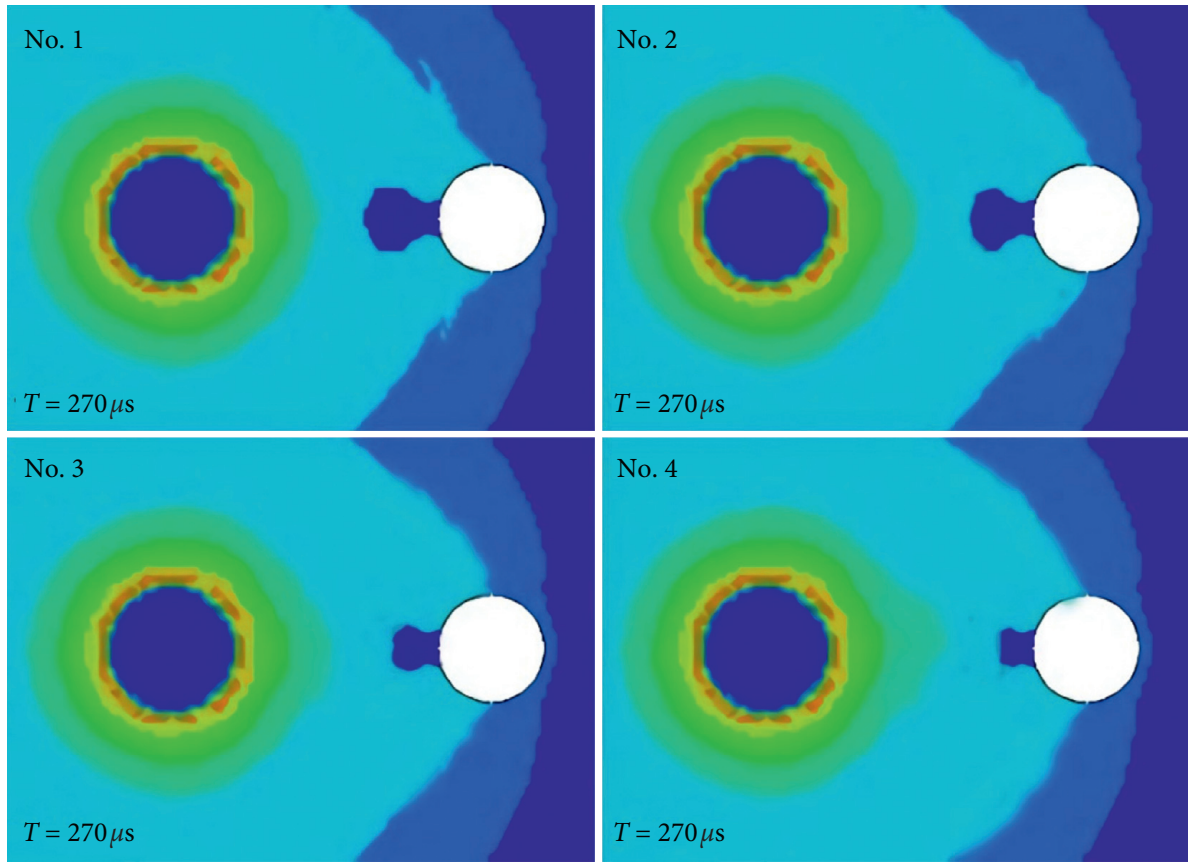

(a)

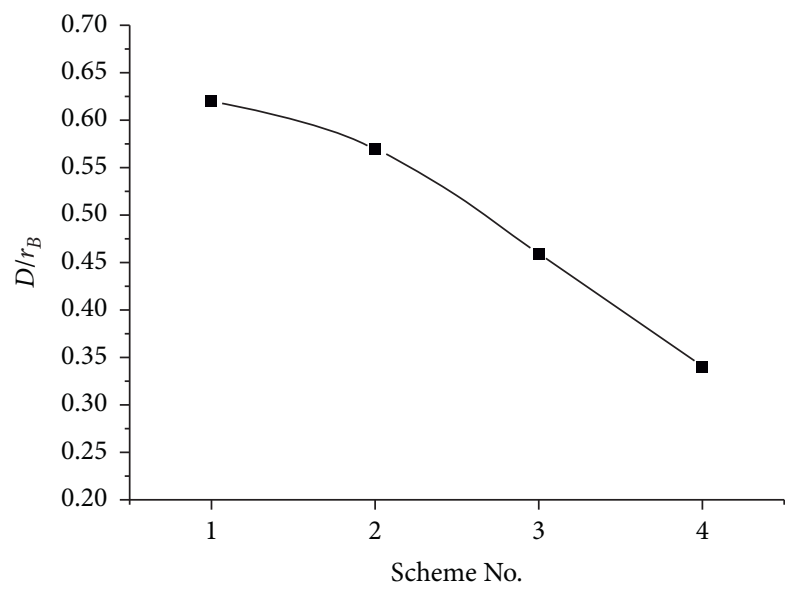

(b)

Figure 4: Cloud chart of dynamic stress distribution around the empty hole in combined stress field and curves of changes in tension zone for Scheme I. (a) Cloud chart of dynamic stress distribution in combined stress field. (b) Changes in the tension zone.

with the changes in the horizontal stress field. Figure 9 shows the curves reflecting the changes in stress at 2081 points under the action of the combined stress field for Scheme III.

From Figures 8 and 9, it can be found that with the increase in horizontal stress (from $0 \mathrm{MPa}$ to $10 \mathrm{MPa}$ ) and lateral pressure coefficient $\lambda$, the tension zone near the empty hole increases $\left(D / r_{B}\right.$ increases from 0.56 to 0.63$)$, and the initial combined compressive stress around the empty hole decreases (from $21.57 \mathrm{MPa}$ to $12.63 \mathrm{MPa}$ ) while the combined tensile stress increases (from $37.02 \mathrm{MPa}$ to 46.45 MPa). These phenomena indicate that when empty holes are arranged horizontally, the impact of the horizontal-vertical field on the empty-hole effect during blasting is opposite to that of the vertical stress field. In other words, the increase in horizontal stress can facilitate the tensile failure of rock mass around the empty hole and inhibit the compressive failure of the same rock mass.

Through a comparative analysis of Figures 4,6 , and 8 , it can be found that when empty holes are arranged horizontally, as vertical and horizontal stresses increase at the same time (while lateral pressure coefficient $\lambda$ remains unchanged), the tension zone in the rock mass around the empty hole still decreases, indicating that vertical stress field has a greater impact on empty-hole effect than horizontal stress field. Considering the symmetrical model arrangement and the direction of applied stress, it is believed that the impacts of horizontal and vertical stress fields on the empty hole when empty holes are arranged vertically are opposite to those when empty holes are arranged horizontally. In other words, the horizontal stress field facilitates the 


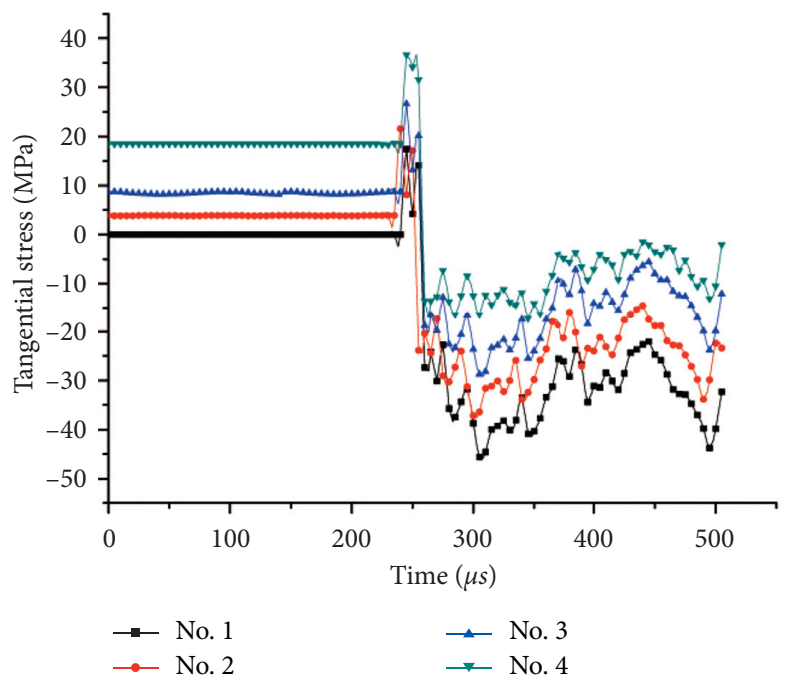

Figure 5: Curves of changes in stress at calculated points under the action of the combined stress field.
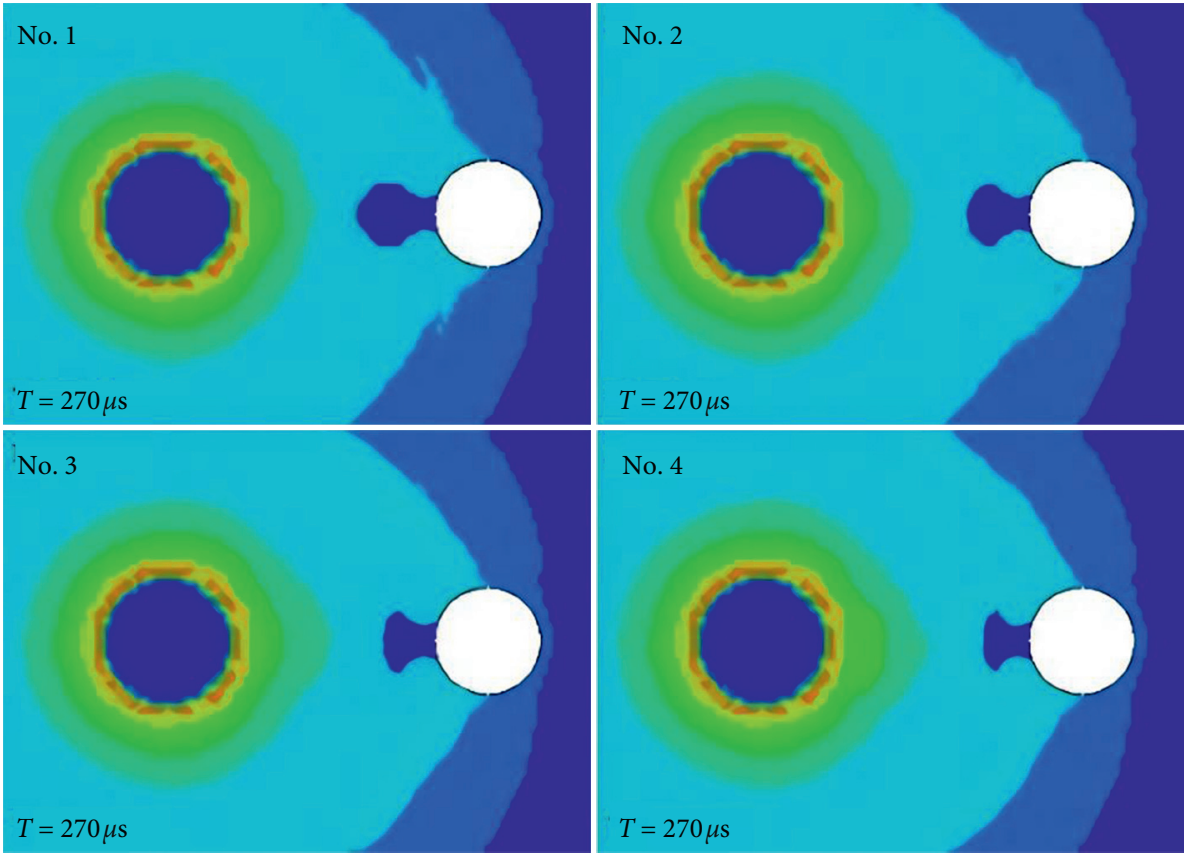

(a)

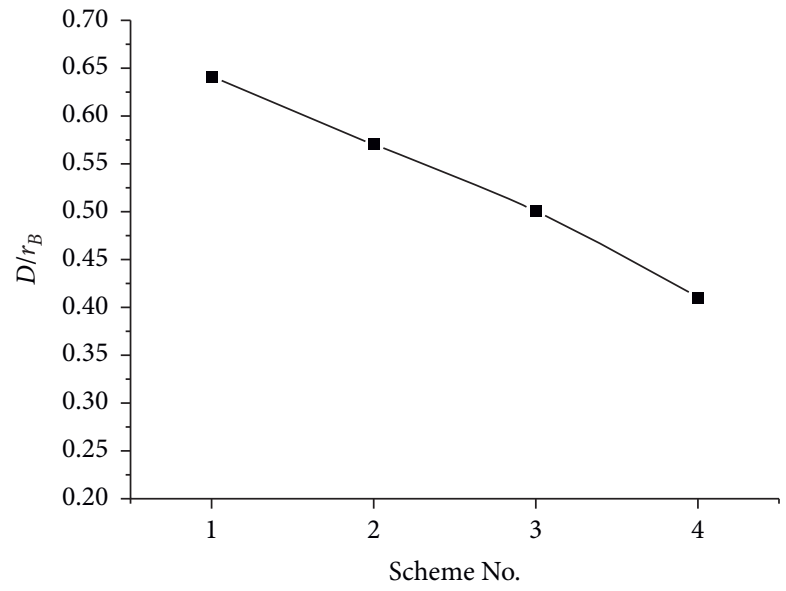

(b)

Figure 6: Cloud chart of dynamic stress distribution around the empty hole in combined stress field and curves of changes in tension zone for Scheme II. (a) Cloud chart of dynamic stress distribution in combined stress field. (b) Changes in the tension zone. 


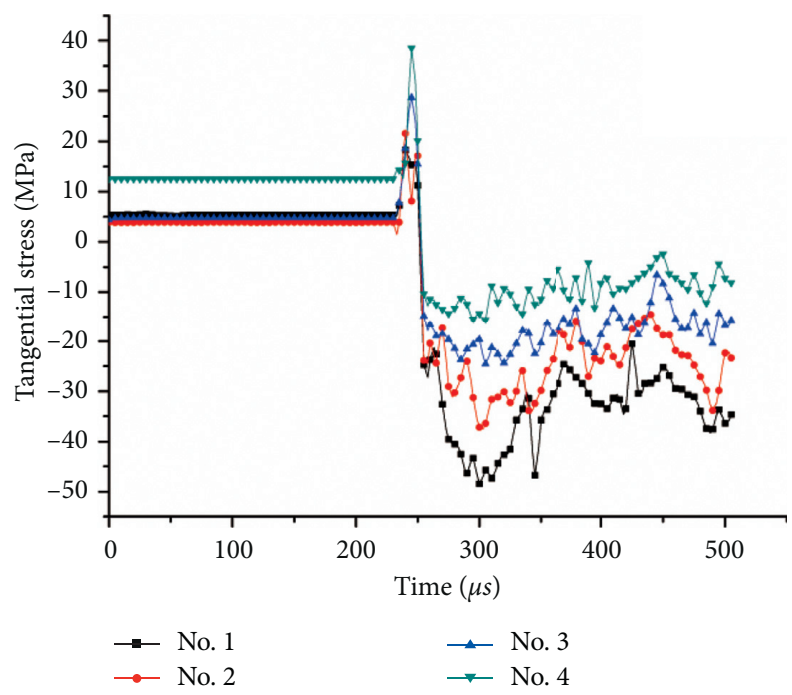

Figure 7: Curves of changes in stress at calculated points under the action of the combined stress field.
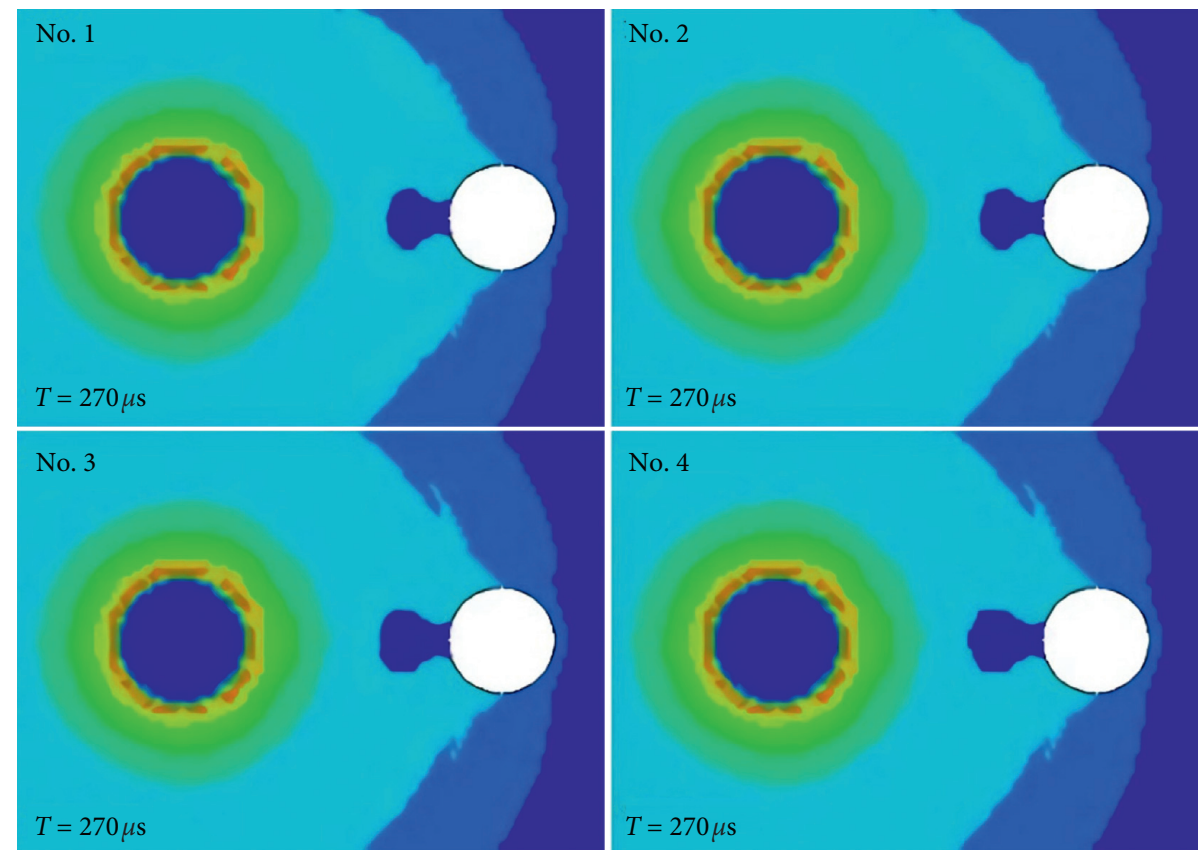

(a)

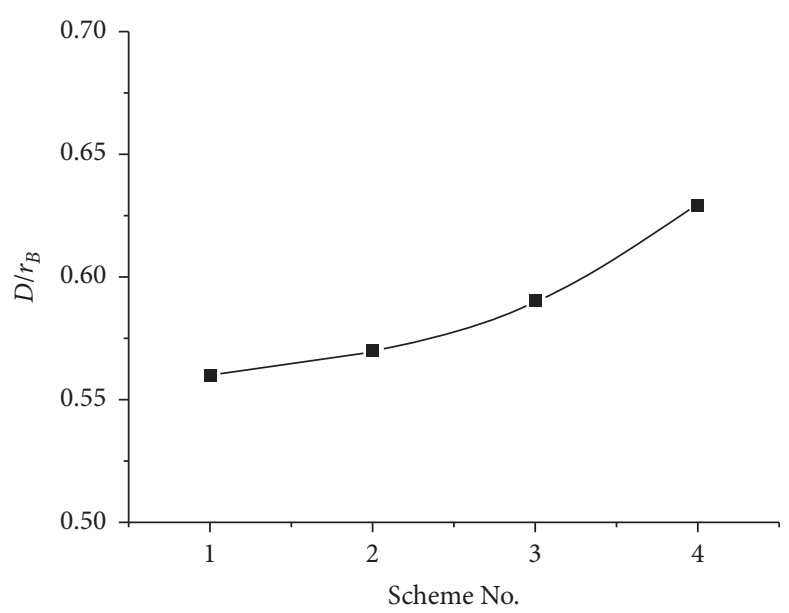

(b)

Figure 8: Cloud chart of dynamic stress distribution around the empty hole in combined stress field and curves of changes in tension zone for Scheme III. (a) Cloud chart of dynamic stress distribution in combined stress field. (b) Changes in the tension zone. 




FIGURE 9: Changes in stress at calculated points under the action of the combined stress field.

compressive failure of the rock mass near the empty hole while the vertical stress field facilitates the tensile failure of the same rock mass. Additionally, the horizontal stress field has a greater impact on the empty-hole effect than the vertical stress field. Therefore, in practice, consideration may be given to arranging empty holes vertically and horizontally at varying spacing to reduce the impact of the in situ stress field.

\section{Theoretical Verification}

Under explosive stress conditions, it should be noted that the maximum tensile stress around the empty hole is achieved on the edge of the empty hole near the blast hole [38]. The maximum tensile stress is calculated as follows:

$$
\left(\sigma_{\theta B}\right)_{1}=\left(1+3 \lambda_{d}\right) P\left(\frac{r_{A}}{L-r_{B}}\right)^{\theta},
$$

where $r_{A}$ is the radius of the blast hole, $r_{B}$ is the radius of the empty hole, $L$ is the distance between the centers of the blast and empty holes, $P$ is the peak of penetrating pressure on the wall of the blast hole after detonation, $\theta=2-\left(\mu_{d} / 1-\mu_{d}\right)$ is the coefficient of stress wave attenuation, $\mu_{d}$ is the dynamic Poisson's ratio of the rock mass, and $\lambda_{d}=\left(\mu_{d} / 1-\mu_{d}\right)$ is the dynamic lateral pressure coefficient.

Also, the approximate solution to the stress around the empty hole under in situ stress conditions can be found using the Schwarz alternating iteration method based on elastic mechanics [39].

$$
\begin{aligned}
\sigma_{r}+\sigma_{\theta} & =4 R_{e}\left[\varphi_{1}^{\prime}(z)\right], \\
\sigma_{\theta}-\sigma_{r}+2 i \tau_{r \theta} & =2\left[\bar{z} \varphi_{1}^{\prime \prime} t(z) n+q \psi_{1}^{\prime} h(z)\right] e^{2 i a},
\end{aligned}
$$

where $a$ is the angle between the horizontal axis and the line between the centers of calculated point and empty hole B, $\varphi_{1}(z)$ and $\psi_{1}(z)$ are two complex variable functions in $X_{B} O_{B} Y_{B}$ coordinate system, $\mathrm{z}$ denotes the coordinates of a calculated point in $X_{B} O_{B} Y_{B}$ coordinate system, which are expressed in plural form when finding solutions to the complex variable functions, and $\sigma_{\theta}, \sigma_{r}$, and $\tau_{r \theta}$ are the radial stress, tangential stress, and shear stress around the empty hole, respectively.

When the calculated point is located at the wall of the empty hole, according to (2), the stress in the in situ stress field is

$$
\left(\sigma_{\theta B}\right)_{2}=2 R_{e}\left[\varphi_{1}^{\prime}(z)\right]+\left[\bar{z} \varphi_{1}^{\prime \prime} t(z) n+q \psi_{1}^{\prime} h(z)\right] e^{2 i a} .
$$

The maximum tensile stress around the empty hole under the action of the in situ stress field during blasting is obtained by coupling the two:

$$
\left(\sigma_{\theta B}\right)_{\max }=2 R_{e}\left[\varphi_{1}^{\prime}(z)\right]+\left[\bar{z} \varphi_{1}^{\prime \prime} t(z) n+q \psi_{1}^{\prime} h(z)\right] e^{2 i a}+\left(1+3 \lambda_{d}\right) P\left(\frac{r_{A}}{L-r_{B}}\right)^{\theta} .
$$

The reasoning assumptions for the above formulas are as follows: (1) the model is calculated as a binary plane; (2) the rock medium is uniform, and the rock failure belongs to the elastoplastic failure criterion; and (3) the distribution of the original rock stress field is assumed to be vertical stress field and horizontal stress field. The above assumptions are consistent with the numerical simulation conditions, so the above formula can be used to verify the numerical simulation results.

The theoretical values of maximum tensile stress around the empty hole for different in situ stress loading schemes are calculated using formula (4) and compared with the results of numerical simulation, as shown in Figure 10.
It should be noted that there are certain differences between the theoretically calculated values and the results of the numeral simulation, and the numerical simulation value is slightly smaller than the theoretical calculation value (see Figure 10). The reason for the analysis is in the theoretical analysis, the stress value includes the blasting thermal damage effect, and in the numerical simulation model, this part of the thermal damage effect generated during blasting is calculated separately. In the rock, the thermal effect decay rate is obviously stronger than the blasting stress benefit, so the theoretical calculation value is larger than the numerical simulation value. Nevertheless, the law of change and trend of the two are 


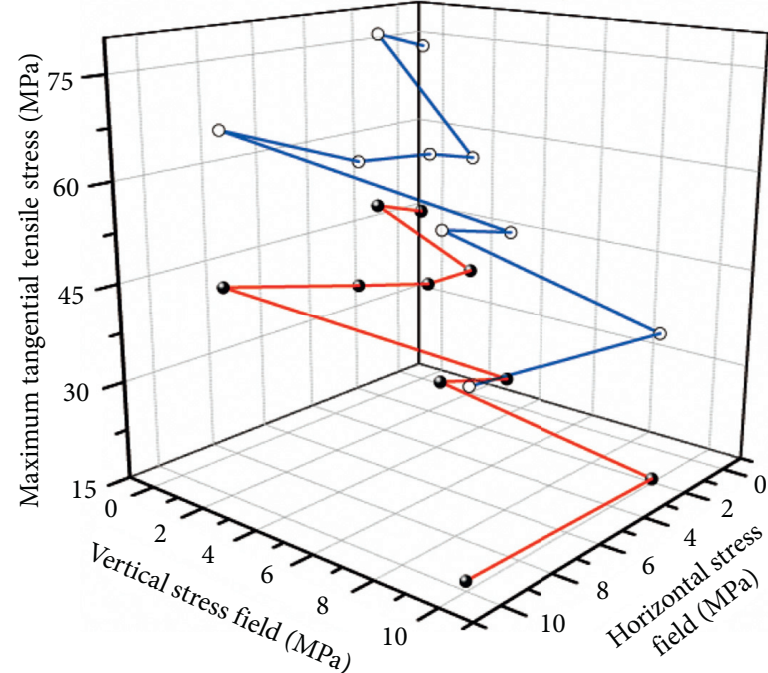

- Results of numerical simulation

- - Results of theoretical calculation

FIGURE 10: Comparison of the values of maximum tensile stress.

consistent. The agreement between the theoretical calculation results and the numerical simulation results has verified the accuracy of the numerical simulation.

\section{Conclusion}

In this study, the distribution and the trend of changes in dynamic stress around the empty hole under different in situ stress conditions during blasting are effectively simulated using ANSYS/LS-DYNA software and implicit-explicit analysis method. The conclusion to this study can be summarized as below $[11,18]$ :

(1) The results of numerical simulation indicate that the overall increase in in situ stress can inhibit the tensile failure of rock mass near the wall of the empty hole and facilitate the compressive failure of the same rock mass.

(2) For horizontally arranged empty holes, the vertical stress field facilitates the compressive failure of rock mass around the empty hole and inhibits the tensile failure of the same rock mass, and the impact of the horizontal stress field is opposite to that of the vertical stress field. In general, when empty holes are arranged horizontally, the vertical stress field has a greater impact on the empty-hole effect than the horizontal stress field. As the symmetrical model arrangement and the direction of applied stress are considered, it is believed that the impacts of horizontal and vertical stress fields on vertically arranged empty holes are opposite to those on horizontally arranged empty holes.

(3) The comparison between the values of maximum tensile stress obtained through theoretical calculation and numerical simulation for the same unit near the wall of the empty hole shows that the rules of changes reflected in these results are consistent, indicating that the results of numerical simulations are accurate.

\section{Data Availability}

All data generated or analyzed during this study are included within this article.

\section{Disclosure}

The findings presented herein are those of the authors and do not necessarily reflect the views of the sponsor.

\section{Conflicts of Interest}

The authors declare that they have no conflicts of interest.

\section{Acknowledgments}

This study was supported by the Foundation of Education Department of Fujian Province (Science and Technology) (JAT190459) and Natural Fund Project of Fujian Province Science and Technology Department (2020J0212307). The authors gratefully acknowledge the support.

\section{References}

[1] Q. Li, D. Luo, W. Wang, Z. Wu, and D. Sun, "A case study on one shot raise driving using multi-spherical charges in an open pit mine," in Rock Dynamics and Applications, vol. 3, pp. 629-634, CRC Press, Boca Raton, FL, USA, 2018.

[2] P. G. Ranjith, J. Zhao, M. Ju, R. V. S. De Silva, T. D. Rathnaweera, and A. K. M. S. Bandara, "Opportunities and challenges in deep mining: a brief review," Engineering, vol. 3, no. 4, pp. 546-551, 2017.

[3] S.-R. Hu, J.-C. Peng, C. Huang, P. Chen, and M. Li, “An overview of current status and progress in coal mining of the deep over a kilometer," China Mining Magazine, vol. 20, no. 7, pp. 105-110, 2011.

[4] B. Lund and M. D. Zoback, "Orientation and magnitude of in situ stress to $6.5 \mathrm{~km}$ depth in the Baltic shield," International Journal of Rock Mechanics and Mining Sciences, vol. 36, no. 2, pp. 169-190, 1999.

[5] C. Fairhurst, "Some challenges of deep mining," Engineering, vol. 3, no. 4, pp. 527-537, 2017.

[6] S. J. Gibowicz and A. Kijko, An Introduction to Mining Seismology, Elsevier, Amsterdam, Netherlands, 2013.

[7] W. P. Huang, Q. Yuan, Y. L. Tan et al., "An innovative support technology employing a concrete-filled steel tubular structure for a $1000 \mathrm{~m}$-deep roadway in a high in situ stress field," Tunnelling and Underground Space Technology, vol. 73, pp. 26-36, 2018.

[8] P. Yan, W.-B. Lu, M. Chen, Y.-G. Hu, C.-B. Zhou, and $\mathrm{X} . \mathrm{X}$. Wu, "Contributions of in-situ stress transient redistribution to blasting excavation damage zone of deep tunnels," Rock Mechanics and Rock Engineering, vol. 48, no. 2, pp. 715-726, 2015.

[9] Q.-Y. Li, G. Chen, D.-Y. Luo, H.-P. Ma, and Y. Liu, "An experimental study of a novel liquid carbon dioxide rockbreaking technology," International Journal of Rock Mechanics and Mining Sciences, vol. 128, Article ID 104244, 2020. 
[10] X. Li, J. Zhou, S. Wang, and B. Liu, "Review and practice of deep mining for solid mineral resources," Chinese Journal of Nonferrous Metals, vol. 27, no. 7, pp. 1236-1262, 2017.

[11] D. Zhu, Y. Wu, Z. Liu, X. Dong, and J. Yu, "Failure mechanism and safety control strategy for laminated roof of wide-span roadway," Engineering Failure Analysis, vol. 111, Article ID $104489,2020$.

[12] L. Castro, R. Bewick, and T. Carter, "An overview of numerical modelling applied to deep mining," in Innovative Numerical Modelling in Geomechanics, pp. 393-414, Taylor \& Francis Group, Oxfordshire, UK, 1st edition, 2012.

[13] S. Heidari, M. Moosavi, and M. Rahimi, "In situ stress measurements of two hydropower projects in Iran by hydraulic fracturing method," Arabian Journal of Geosciences, vol. 8, no. 9, pp. 7073-7085, 2015.

[14] A. M. Lucier, M. D. Zoback, V. Heesakkers, Z. E. Reches, and S. K. Murphy, "Constraining the far-field in situ stress state near a deep South African gold mine," International Journal of Rock Mechanics and Mining Sciences, vol. 46, no. 3, pp. 555-567, 2009.

[15] H. Zhao, F. Ma, J. Xu, and J. Guo, "In situ stress field inversion and its application in mining-induced rock mass movement," International Journal of Rock Mechanics and Mining Sciences, vol. 53, pp. 120-128, 2012.

[16] M. Cai and H. Peng, "Advance of in-situ stress measurement in China," Journal of Rock Mechanics and Geotechnical Engineering, vol. 3, no. 4, pp. 373-384, 2011.

[17] P. M. Thompson and N. A. Chandler, "In situ rock stress determinations in deep boreholes at the underground research laboratory," International Journal of Rock Mechanics and Mining Sciences, vol. 41, no. 8, pp. 1305-1316, 2004.

[18] D. Zhu, X. Song, H. Li, Z. Liu, C. Wang, and Y. Huo, "Cooperative load-bearing characteristics of a pillar group and a gob pile in partially caved areas at shallow depth," Energy Science \& Engineering, vol. 8, no. 1, pp. 89-103, 2020.

[19] P. W. Chen, T. Huang, J. Yang, and G. X. Zhang, "Numerical simulation of rock fracture under dynamic loading using Manifold method," Key Engineering Materials, vol. 324-325, pp. 235-238, 2006.

[20] A. Zubelewicz and Z. Mróz, "Numerical simulation of rock burst processes treated as problems of dynamic instability," Rock Mechanics and Rock Engineering, vol. 16, no. 4, pp. 253-274, 1983.

[21] R. S. Yang, Y. L. Che, X. Tong, Y. L. Mi, and L. Feng, "Experimental study on the technology of middle empty hole in parallel hole cut blasting," Advanced Materials Research, vol. 594-597, 2012.

[22] B. Dai and Y. Chen, "A novel approach for predicting the height of the water-flow fracture zone in undersea safety mining," Remote Sensing, vol. 12, no. 3, p. 358, 2020.

[23] A. Godio and J. Seccatore, "Measuring the reduction of the confinement along the evolution of a burn cut," Applied Sciences, vol. 9, no. 23, p. 5013, 2019.

[24] N. Meng, J. Bai, Y. Chen et al., "Damage evolution mechanisms of rock induced by blasting with the aid of empty-hole effect," Energies, vol. 13, no. 3, p. 756, 2020.

[25] Y. Zhongwen, G. Yang, X. Peng, W. Xu, and S. Yao, “Analysis of empty hole effect in directional fracture controlled blasting," Explosion and Shock Waves, vol. 35, no. 3, pp. 304-311, 2015.

[26] Q.-Y. Li, M. Xu, Z.-P. Fan, and W.-H. Wang, "Simulation of rock failure process in cutting by parallel hole and analysis on empty hole effect," Blasting, vol. 28, no. 4, pp. 23-26, 2011.
[27] H. Wang, Q. Zong, and Y. Zhao, "Numerical analysis and application of large diameter cavity parallel cut blasting stress field in vertical shaft," Chinese Journal of Rock Mechanics and Engineering, vol. 34, no. S1, pp. 3223-3229, 2015.

[28] Z. Zheng, Y. Xu, J. Dong, Q. Zong, and L. Wang, "Hard rock deep hole cutting blasting technology in vertical shaft freezing bedrock section construction," Journal of Vibroengineering, vol. 17, no. 3, pp. 1105-1119, 2015.

[29] H. John, LS-DYNA Theoretical Manual-Version 970, Livermore Software Technology Corporation, Livermore, CA, USA, 2005.

[30] F. AyalaCarcedo, Drilling and Blasting of Rocks, Routledge, Abingdon, UK, 2017.

[31] B. Damjanac, M. Board, M. Lin, D. Kicker, and J. Leem, "Mechanical degradation of emplacement drifts at Yucca Mountain-A modeling case study," International Journal of Rock Mechanics and Mining Sciences, vol. 44, no. 3, pp. 368-399, 2007.

[32] G. W. Ma and X. M. An, "Numerical simulation of blastinginduced rock fractures," International Journal of Rock Mechanics and Mining Sciences, vol. 45, no. 6, pp. 966-975, 2008.

[33] Z. Wu, D. Luo, and G. Chen, "Design and realization of the intelligent design system for tunnel blasting in mine based on database," Geofluids, vol. 2020, Article ID 8878783, 2020.

[34] Z. Zhao, G. Tao, and C.-X. Du, "Application research on JWL equation of state of detonation products," Chinese Journal of High Pressure Physics, vol. 4, 2009.

[35] Y. Wang, "Experimental research on the influence of an empty-hole defect on crack connections between a directionally fractured blast hole," Journal of Testing and Evaluation, vol. 45, no. 6, pp. 2139-2150, 2017.

[36] C. Zhai, J. Xu, S. Liu, and L. Qin, "Fracturing mechanism of coal-like rock specimens under the effect of non-explosive expansion," International Journal of Rock Mechanics and Mining Sciences, vol. 103, pp. 145-154, 2018.

[37] U. Langefors and B. Kihlström, The Modern Technique of Rock Blasting, Wiley, Hoboken, NJ, USA, 1978.

[38] Z. Wu, Q. Li, D. Kong, G. Chen, and D. Luo, "The ANPFuzzy-TOPSIS model for the optimization of the scheme of large-section blasting," Arabian Journal of Geosciences, vol. 13, no. 2, pp. 1-9, 2020.

[39] C. Martin, P. Kaiser, and R. Christiansson, "Stress, instability and design of underground excavations," International Journal of Rock Mechanics and Mining Sciences, vol. 40, no. 78, pp. 1027-1047, 2003. 